\title{
Introducing the World Society for Transport and Land Use Research
}

\author{
Kevin Krizek \\ University of Colorado ${ }^{\mathrm{a}}$ \\ Kelly J. Clifton \\ Portland State University ${ }^{b}$
}

The excitement that many brought to the Journal of Transport and Land Use (JTLU) over the past five years and its rapid success - as measured by number of quality submissions, breadth of the research reported, and number of downloaded articles-suggests a broad and healthy research community. To provide the opportunity for a face-to-face research exchange, JTLU co-sponsored the inaugural World Symposium on Transport and Land Use Research (WSTLUR) in July 2011.

WSTLUR attracted more than 70 participants from around the world. Taking its cue from the WSTLUR acronym, the event was held July 28-30 in Whistler, British Columbia. The symposium was organized by the Center for Transportation Studies (University of Minnesota) with support from the Georgia Transportation Institute, University of California Transportation Center, UC Davis Sustainable Transportation Center, University of Connecticut Center for Transportation and Livable Systems, University of Vermont Transportation Research Center, University of Colorado Boulder College of Architecture and Planning, University of Colorado Denver College of Engineering and Applied Science, and Transport Canada.

Highlights included plenary presentations by Ed Glaeser, Fred and Eleanor Glimp Professor of Economics at Harvard University; Robert Cervero, Carmel P. Friesen Chair in Urban Studies and professor of City and Regional Planning at the University of California, Berkeley; and David Banister, Professor of Transport Studies at Oxford University. All submissions were peer reviewed for possible publication in JTLU, the official journal for the symposium. We received 72 original research submissions, many of which will be found in subsequent issues.

Looking forward, it was important to formalize the process for the next WSTLUR (anticipated in 2014) and provide a forum for scholarly land use-transport activities. To fill this

\footnotetext{
${ }^{a}$ Professor of Planning and Design; Chair, Inaugral World Symposium on Transport and Land Use Research

${ }^{\mathrm{b}}$ Associate professor of Civil Engineering; Chair, World Society for Transport and Land Use Research
}

Copyright 2011 Kevin Krizek and Kelly J. Clifton.

Licensed under the Creative Commons Attribution - NonCommercial License 3.0. need, the symposium launched the World Society for Transport and Land Use Research, a group that in its infancy comprises more than 120 members. A board of 11 was elected by the members (plus two ex officio members). The board then selected its officers (with affiliation and terms):

- Chair - Kelly J. Clifton, Associate Professor, Civil and Environmental Engineering, Portland State University (2012-2015)

- Vice-Chair - Corinne Mulley, Chair in Public Transport, Institute of Transport and Logistics Studies, University of Sydney (2012-2018)

- Secretary - Lei Zhang, Assistant Professor, Department of Civil and Environmental Engineering, University of Maryland-College Park (2012-2015)

- Treasurer - Jason (Xinyu) Cao, Assistant Professor, University of Minnesota (2012-2015)

- Co-chair of 2014 symposium - Ahmed El-Geneidy, Assistant Professor, McGill University

After a productive and exciting year, the result is an administrative triumvirate-a journal, symposium, and society-to serve as a much-needed home for cutting edge land use-transport scholarship. As we look forward to the exciting work ahead, we encourage you to visit the WSTLUR website (http://www.wstlur.org) and join us in these endeavors. 